\title{
The Electrochemical Migration Phenomenon of the Ni-Cr Seed Layer of Sputtered FCCL
}

\author{
Woo-young Ahn ${ }^{\mathrm{a}}$, Joong soon Jang ${ }^{\mathrm{b}^{*}}$ \\ a3M AST Ltd, Cheonan 331-290, Korea \\ ${ }^{b}$ Department of Industrial Engineering, Ajou University, Suwon 443-749, Korea
}

(Received February 13, 2014 ; revised March 17, 2014 ; accepted April 1, 2014)

\begin{abstract}
As the demand for fine-pitch FPCB (Flexible Printed Circuit Board) increases, so do the number of applications of sputtered FCCL (Flexible Copper Clad Laminate). Furthermore, as the width between the circuit patterns decreases, greater defects are observed in the migration phenomenon. In this study we observed changes in ion migration in real circuit-pattern width using sputtered FCCL. We found that as the applied voltage and residue thickness of the $\mathrm{NiCr}$ seeds increase, ion migration occurs faster. If the $\mathrm{NiCr}$ seed layer thickens due to a high cathode power and long deposition time while being sputtered, the NiCr will form a residue that quickly becomes a factor for incurring ion migration.
\end{abstract}

Keywords: Ion migration, Electrochemical migration, Sputtered FCCL, NiCr seed layer, Circuit short

\section{Introduction}

One of the most popular topics today is smartphones. In terms of the evolution of smartphones, performance enhancement is occurring rapidly. The technological advancement of the touch sensor module (TSM) and flexible printed circuit board (FPCB), which are circuits for signal transmission in main boards and TSP (Touch Screen Panel)s, is revolutionary. In this study we examine and analyze electrochemical ion migration $(\mathrm{ECM})$ according to the changing thickness of the NiCr alloy, which constitutes the seed layer of sputtered FCCL and is a necessary raw material in FPCB of $50 \mu \mathrm{m}$ pitch and under. The ECM phenomenon is linked to the life reliability of all electronic parts that are composed of circuits. Although several analyses of ECM in the FPCB (using casting FCCL as a raw material) of general pitch sizes have been reported, sputtered FCCL combined with ECM has yet to be examined.

Lithium-ion batteries are used in many different kinds of portable electronic devices. For instance, the

\footnotetext{
${ }^{*}$ Corresponding author. E-mail : jsjang@ajou.ac.kr
}

electrode link wiring of batteries is printed into $\mathrm{Ag}$ paste. Because ECM occurs at high temperatures and in moist conditions, it is one of the leading causes of the shortened lifespan of portable devices ${ }^{4}$. In the case of circuits wired by $\mathrm{Cu}, \mathrm{ECM}$ can be prevented using a tin coating. At the same time, the bonding of components can be improved. In the water drop test where humidity is $100 \%$, ECM occurs ${ }^{1,2)}$ where dendrites are growing.

If migration occurs when circuit-surface-gilt matter is observed, the surface treatment of $\mathrm{Au}, \mathrm{Pd}$, and $\mathrm{Ni}$ on the Cu-circuit migration decreases ${ }^{3}$. However, when the insulation resistance between the circuits patterns on the surface gilt mixed with $\mathrm{Ag}$ or $\mathrm{Cu}$, an environment ${ }^{5)}$ conducive to ECM is created. In a test environment (bias $40 \mathrm{~V}, 65^{\circ} \mathrm{C}, 88 \%$ humidity) of the $\mathrm{Cu}$ circuit, ECM could not be observed in the circuit to which a solder mask (SM) had been applied when the ECM changed in relation to the SM application ${ }^{6,16}$ (Table 1).

The materials of the SM indicate that dendrites are larger and occur more frequently in lead-free (64Sn-35Bi-1 Ag) solder than in $\mathrm{SnPb}$ solder. In the experimental environment $(3.5 \mathrm{~g} / l \mathrm{NaCl})$, $\mathrm{Sn}$ was 
Table 1. Test matrix failure pattern for four boards processed with different factors

\begin{tabular}{|c|c|c|c|c|c|c|}
\hline \multirow{2}{*}{ Solder } & \multirow{2}{*}{ Finish } & \multirow{2}{*}{ Solder Mask } & \multicolumn{3}{|c|}{ SIR Failure Times (hours)* } & \multirow{2}{*}{$\begin{array}{c}\text { Dendritic } \\
\text { Growth }\end{array}$} \\
\hline & & & Sample 1 & Sample 2 & Sample 3 & \\
\hline \multirow{2}{*}{$\mathrm{SnPb}$} & \multirow{2}{*}{$\begin{array}{c}\mathrm{SnPb} \\
\mathrm{HASL}\end{array}$} & $\mathrm{SM}$ & $\mathrm{s}$ & $\mathrm{s}$ & $\mathrm{s}$ & None \\
\hline & & No SM & 106 & 49 & 36 & Extensive \\
\hline \multirow{2}{*}{ SAC } & \multirow{2}{*}{$\begin{array}{c}\text { SAC } \\
\text { HASL }\end{array}$} & SM & $\mathrm{s}$ & $\mathrm{s}$ & $\mathrm{s}$ & 1 place \\
\hline & & No SM & 15 & 16.2 & 11.5 & Extensive \\
\hline
\end{tabular}

*Note : "s" means the sample survived the test and did not fail; "SM" means that the sample had a solder mask; "No SM" means that no solder mask was present.

most frequently observed in the components of the dendrites $^{8,14)}$. The results show that the main components of dendrites overlap with some of the $\mathrm{Cu}$ circuit components and are mostly found in the coating matter of the circuit surface.

An analysis of the formation mechanism of dendrites through the water drop test of a pure circuit without a surface coating indicated that a short circuit is formed over time due to the growth of dendrites ${ }^{9}$. When ECM was compared in the water drop test using ion water and sea water, ECM was actively processed in sea water ${ }^{10,13)}$, suggesting that the chloride in sea water helps ion exchange occur in the form of dendrites. Dendrites have therefore been shown to grow over time due to the ECM phenomenon ${ }^{17)}$, proving that the growth of dendrites progresses rapidly rather than steadily.

ECM is observed mostly through the water drop test ${ }^{20)}$ to measure the sensitivity of electrochemical migration. The water drop test records the amount of time it takes for distilled water drops and dendrites under $15 \mathrm{~V}$ bias to grow. The maximum current allowance is $1.5 \mathrm{~mA}$. Although this test does not predict long-term reliability, it provides the process conditions for comparison. Furthermore, it allows for local experimental methods rather than the need to examine the whole area of a circuit board. In terms of the shape, width, and space of the PCB pattern, the space between the circuits should be 15-30 mils $(375-750 \mu \mathrm{m})$ and a Y-shape pattern should be used.
However, to check the reliability of electronic device parts, highly integrated circuits, which are loaded like smartphones, can be improper. In this study, ECM defects in microcircuits, a sample of a circuit pattern width for which reliability evaluation is possible. In contrast, the water drop test (using only distilled water) is dealt with in the IPC standard size. Since highdensity mobile devices are increasing in popularity, a saltwater drop test was added to examine human salt. We also analyzed ECM according to the thickness of the seed layer of FCCL. This study can shorten the development time of using the sputtered FCCL which will be a better solution of the fine pitch circuit that is used in mobile electronics. We expect that the results of this study can be applied to the field of electronics reliability.

\section{Experimental Procedure}

We used 25 NPI-grade (thickness $25 \mu \mathrm{m}$ ) sputtered FCCL (Kaneka Co, Japan) For the PI film, Ar and $\mathrm{O}_{2}$ were mixed (50:50) and preprocessed with 2,000 V. $\mathrm{NiCr}$ (ratio 95:5) was deposited with the following thicknesses: $10 \mathrm{~nm}, 20 \mathrm{~nm}$, and $30 \mathrm{~nm}$. Cu was then sputtered on the NiCr layer at a thickness of $150 \mathrm{~nm}$. On the sputtered side, $\mathrm{Cu}$ was raised to a thickness of $12 \mu \mathrm{m}$ using roll-to-roll copper plating. The completed FCCL was etched onto the circuit at a width of $500 \mu \mathrm{m}$ and a space-width of $13 \mu \mathrm{m}$ in order to make the specimens. For circuit etching,

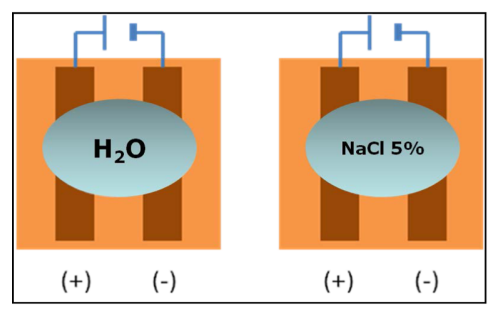

(a)

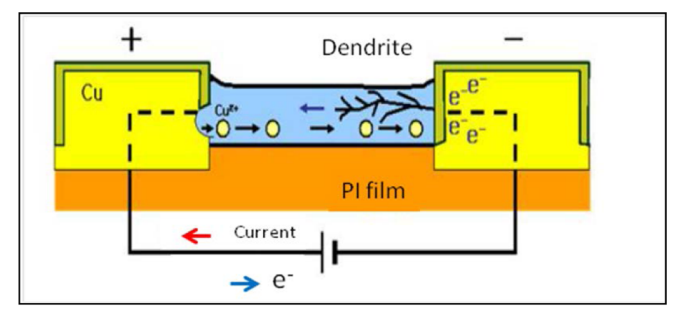

(b)

Fig. 1. (a) Water drop test method, (b) dendrite formation. 
general $\mathrm{FeCl}_{3}$ was used. Four kinds of specimens were applied to the etching time and pressure was applied under the same test conditions. Finally, ECM (according to the nonetching degrees of the seed layer) was observed.

The water drop test was conducted to study ECM (Fig. 1). The environment consisted of $100 \%$ humidity of ion water and a voltage bias $(1 \mathrm{~V}, 2 \mathrm{~V}$, and $3 \mathrm{~V})$. Both the time for dendrite growth and the short current that occurred between the two electrodes were monitored, and dendrite organization was observed. At this time, the permitted current was $10 \mathrm{~mA}$. The dendrites grew on the specimen relative to the thickness of the $\mathrm{NiCr}$ seed layer in the $3 \mathrm{~V}$ condition where growth occurred rapidly. The dendrites were analyzed using EDX (JSM7000F, JEOL).

\section{Results and Discussion}

ECM occurs as a result of adhesion and the absorption of moisture between patterns and space. For ECM to occur, the electrolysis of water must be generated by the applied voltage. Oxidation usually occurs in the positive pole, while $\mathrm{Cu}$ ions elute and move toward the negative pole in the form of $\mathrm{Cu}$ dendrites. $\mathrm{Cu}$ ions take electrons from the negative pole, and these ions grow by being turned back into $\mathrm{Cu}$.

The first sputtering process of the seed layer while changing the thickness of the $\mathrm{NiCr}$ to $10 \mathrm{~nm}, 20 \mathrm{~nm}$, and $30 \mathrm{~nm}$ between the PI and $\mathrm{Cu}$ layers. Next, it deposited the $\mathrm{Cu}$ and made it grow to $12 \mu \mathrm{m}$ with electric gilding. On the etched $\mathrm{Cu}$ side, only PI remained; the $\mathrm{NiCr}$ particles remained as a residue or seed layer. The lower seed layer thickness was the less residue remained.

Only a small amount of nickel was detected during the EDX analysis of the etched P1 side after etching the $\mathrm{NiCr}$ seed FCCL to $10 \mathrm{~nm}$ thickness. $\mathrm{Cr}$ was detected on the $20 \mathrm{~nm} \mathrm{NiCr}$ seed. On the etched side of the $30 \mathrm{~nm}$ seed, a large amount of nickel and a

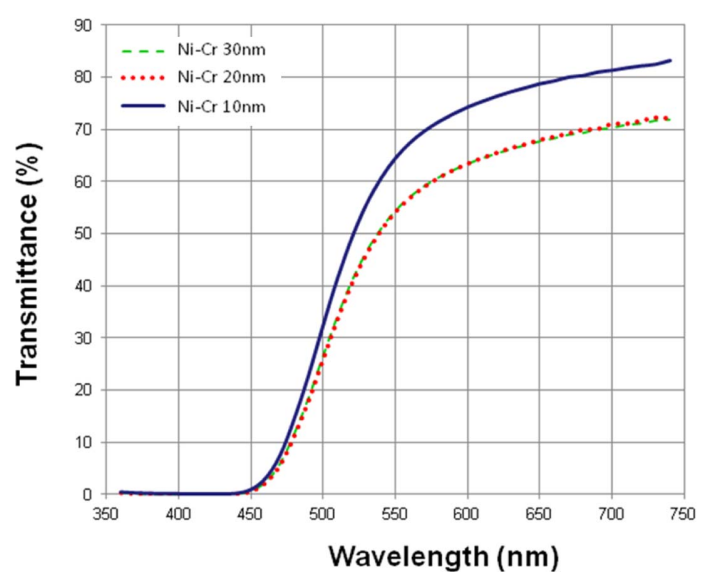

Fig. 3. Transmittance spectra of sputtered FCCL after etching copper using etchants.

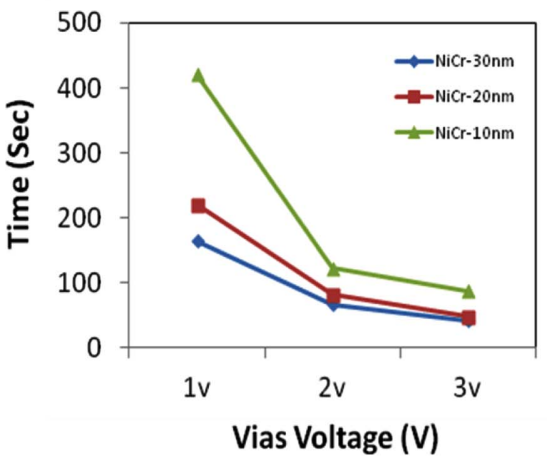

(a)

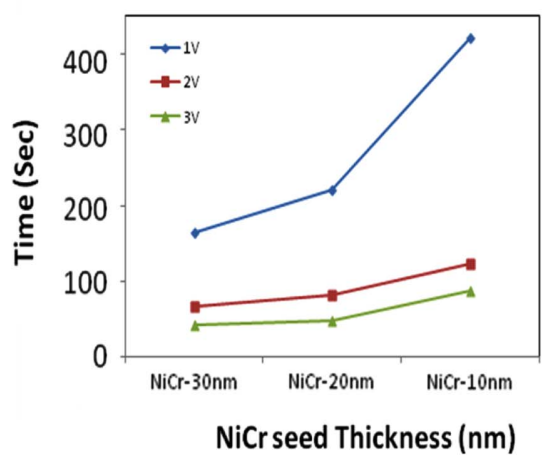

(b)

Fig. 4. Results of electrochemical migration using the $\mathrm{NiCr}$ seed circuit (a) according to bias voltage and (b) according to NiCr seed thickness.

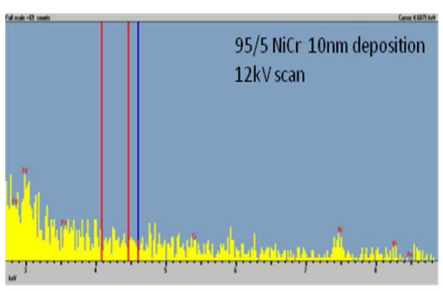

(a)

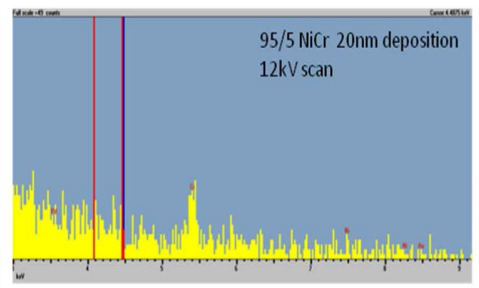

(b)

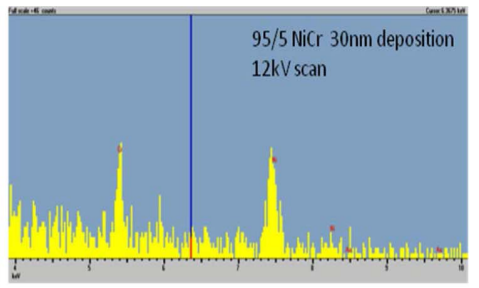

(c)

Fig. 2. EDX analysis of the etched surface. (a) NiCr seed $10 \mathrm{~nm}$, (b) NiCr seed $20 \mathrm{~nm}$, (c) NiCr seed $30 \mathrm{~nm}$. 
little chromium were detected like as Fig. 2(c). To determine the amount of residue after etching, the penetration ratio of the etched side was measured. As seen in Fig. 3, a low penetration ratio was observed for the etched $\mathrm{Pl}$ side of the $\mathrm{NiCr}$ seed layer with $30 \mathrm{~nm}$ thickness. This may mean that a thicker $\mathrm{NiCr}$ seed layer on the $\mathrm{Pl}$ side has more remaining residue.

We can recognize ion migration in Fig. 4 by the thickness and voltage of the $\mathrm{NiCr}$ seed layer in relation to time. Fig. 4(a) shows that a thicker $\mathrm{NiCr}$ seed layer has a faster ECM on the etched surface of the circuit. Similar graphs of $20-\mathrm{nm}-$ and $30-\mathrm{nm}-$ thick $\mathrm{NiCr}$ seed layer samples show that having a seed layer thickness of $20 \mathrm{~nm}$ and greater produces the same environment, which can create the ECM phenomenon. Table 2 shows that seed layer thickness is more influenced in ECM than it is in vias volts. the p-value in the ANOVA table of seed layer thickness is more than 0.05 , this means that there is no significant influence by thickness but there is an influence from bias volts. To determine the effect that $\mathrm{NiCr}$ particles (which form residues in the area between the circuits) have on dendrite growth, the density difference of dendrites was checked by microscope and SEM.

Fig. 5(c) shows that the dendrite is forming layers that are thicker and clearer than those in Fig. 5(a), indicating that the residue from the $\mathrm{NiCr}$ seed layer after the etching process provides a good environment for ECM. The SEM image of the dendrite surface in Fig. 5(c) is shown in Fig. 6(c).

A thick residue from the $\mathrm{NiCr}$ seed layer resulted in a larger dendrite than a thin residue from the $\mathrm{NiCr}$ seed layer, as shown in Fig. 6(c). The elements of the dendrites are shown in Fig. 7. Some Ni was detected in the dendrite structures, indicating that dendrite growth can occur as a result of metal ions being dissolved in a solution at the seed of the

Table 2. Two-way ANOVA: Time versus thickness of $\mathrm{NiCr}$ seed layer, bias volts

\begin{tabular}{|c|c|c|c|c|c|}
\hline Source & df & SS & MS & F & P \\
\hline Thickness of NiCr seed layer & 2 & 23718 & 11859.1 & 3.05 & 0.157 \\
\hline Vias Volts & 2 & 76486 & 38243.1 & 9.84 & 0.028 \\
\hline Error & 4 & 15534 & 3883.4 & & \\
\hline Total & 8 & 115738 & & & \\
\hline
\end{tabular}

$\mathrm{S}=62.32 \mathrm{R}-\mathrm{Sq}=86.58 \% \mathrm{R}-\mathrm{Sq}(\mathrm{adj})=73.16 \%$

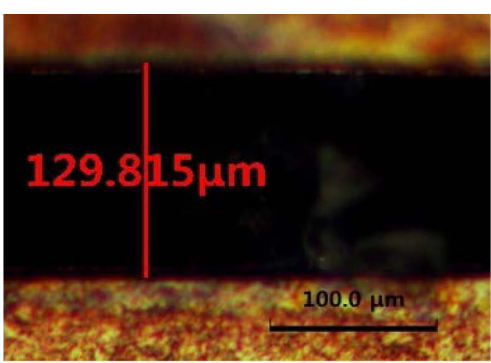

(a)

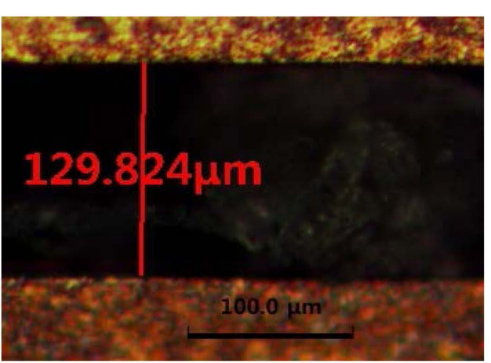

(b)

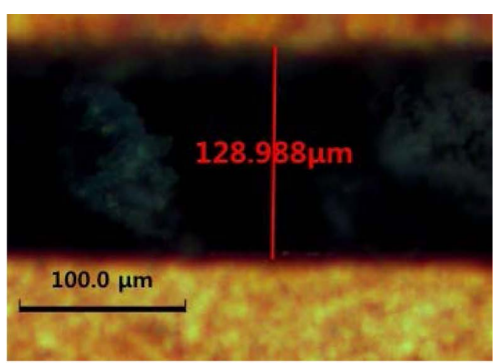

(c)

Fig. 5. Dendrite images between circuit patterns (a) NiCr $10 \mathrm{~nm}$ with 3 V $3 \mathrm{~min}$; (b) $\mathrm{NiCr} 20 \mathrm{~nm}$ with $3 \mathrm{~V} 3 \mathrm{~min}$; (c) $\mathrm{NiCr} 30 \mathrm{~nm}$ with $3 \vee 3 \mathrm{~min}$.

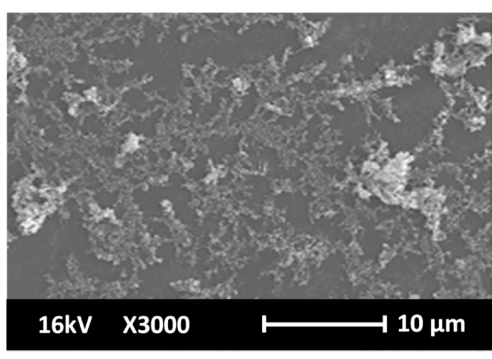

(a)

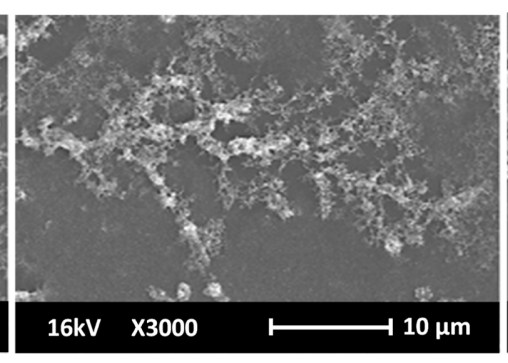

(b)

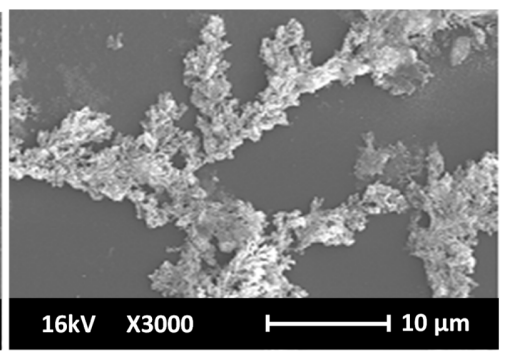

(c)

Fig. 6. SEM image of dendrites. (a) $\mathrm{NiCr}$ seed $10 \mathrm{~nm}$, (b) $\mathrm{NiCr}$ seed $20 \mathrm{~nm}$, (c) $\mathrm{NiCr}$ seed $30 \mathrm{~nm}$. 


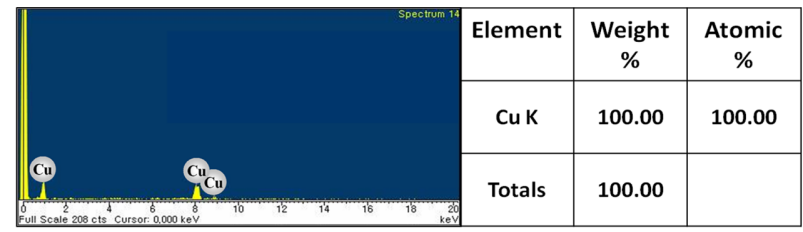

(a)

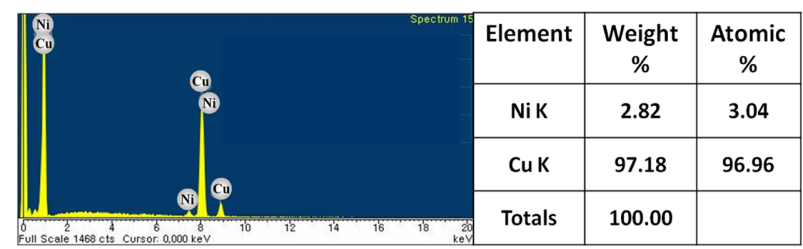

(b)

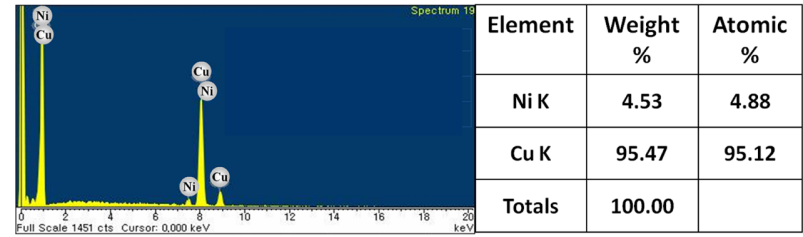

(c)

Fig. 7. EDS analysis of dendrites (a) NiCr seed $10 \mathrm{~nm}$, (b) $\mathrm{NiCr}$ seed $20 \mathrm{~nm}$, (c) NiCr seed $30 \mathrm{~nm}$.

anode, plating out at the cathode through the $\mathrm{Ni}$ ion located in the middle area between the circuit patterns.

\section{Conclusions}

The ECM rate was increased by increasing the bias voltage. The $\mathrm{NiCr}$ residue on the etched area after the chemical etching process by $\mathrm{Ni}$ ions accelerated the growth of ECM. The main element of the dendrite structure was composed of metal objects.

Since ECM is influenced by the thickness of the residue, a minimum supply of voltage is preferred in order to reduce the chances of ECM. Dendrite growth occurs as a result of metal ions being dissolved in a solution at the anode and plating out at the cathode through the $\mathrm{Ni}$ ion located in the middle area of the circuit space. Seed layers of $20 \mathrm{~nm}$ thickness and above have similar environments, which can lead to the ECM phenomenon.

\section{References}

1. X. Zhong, X. Guo, Corrosion Sci., 74 (2013) 71.

2. H. He, F. Guo, Electron. Mater. Lett., 8 (2012) 463.

3. T. G. Woo, K. W. Seol, Electron. Mater. Lett., 8 (2012) 151.

4. N. B. Aguilera, A. Bossche, IEEE Transactions on Device and Materials. Reliability, 13 (2013) 1.

5. D. Konno, N. Yoshimura, IEEJ Transactions on Fundamentals and Materials, 133 (2013) 153.

6. X. He, M. G. Pecht, IPC APEX EXPO Technical Conference (2012).

7. J. B. Chyi, G. S. Shen, Packaging, Assembly, \& Circuit Technology Conference, ISBN 978-1-45771388-0.

8. H. Li, H. Hanna, Wuhan University Journal of Natural Sciences, 17 (2012) 79.

9. V. V. R. Nandigana, N. R. Aluru, Electrochimica Acta, 105 (2013) 514.

10. H. Huang, Z. Dong, Corrosion Science, 53 (2011) 3446.

11. B. I. Noh, S. B. Jung, Mater Electron., 19 (2008) 952.

12. B. Li, D. Badami, Microelectronics Reliability, 44 (2004) 365.

13. M. A. Hussain, F. M. Khoshnaw, IEEE 9th VLSI Packaging Workshop of Japan, 12 (2008) 105.

14. Y. Heng Chen, M. Hsiao, 19th IEEE International Symposium on the Physical and Failure Analysis of Integrated Circuits, 7 (2012) 1.

15. Konno, Dai, Denki Gakkai Ronbunshi, A Kiso zairy $\AA$, 133 (2013) 153.

16. X. He, M. G. Pecht, IPC APEX EXPO Technical Conference, (2010) 1297.

17. K. Mitobe, Denki Gakkai Ronbunshi. A, Kiso zairyA. 127 (2007) 335.

18. D. B. Lee, D. S. Yu, Journal of the Korean Society for Precision Engineering, 9 (2005) 64.

19. D. B. Lee, D. S. Yu, Korean Society for Precision Engineering Meeting (2004) 180.

20. "IPC-TM 650 2.6.13 Test Method Manual," Assessment of Susceptibility to Metallic Dendritic Growth. 2215 Sanders Road Northbook, IL 60062-6135. 